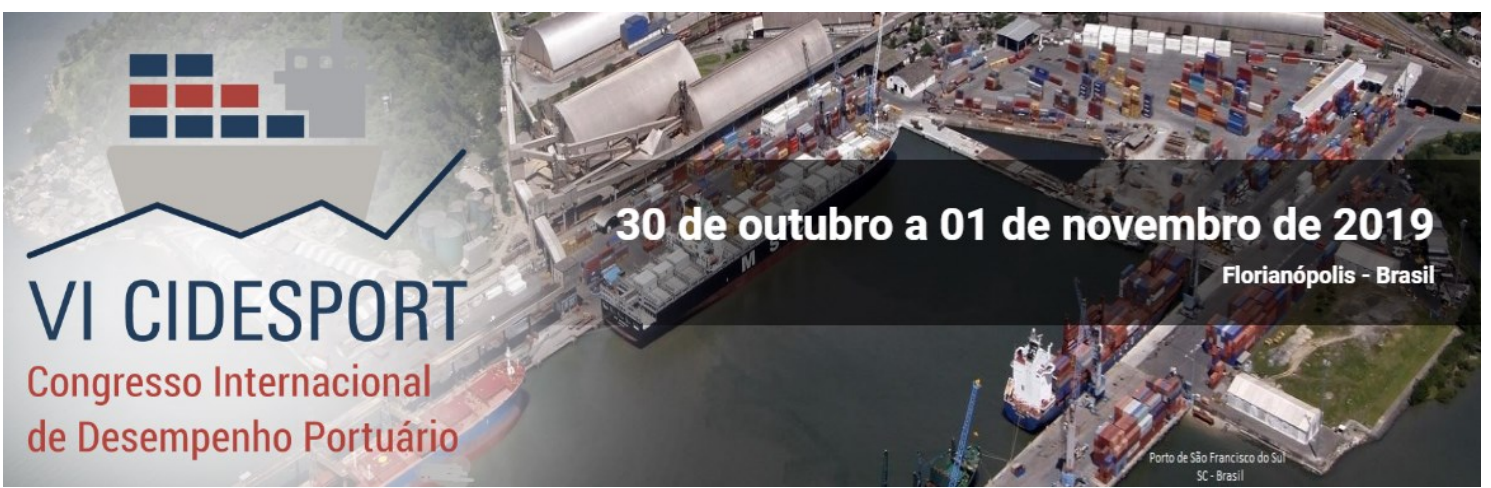

\title{
GESTÃO DA APLICAÇÃO DO ISPS CODE NUM CONTEXTO DE (IN)SEGURANÇA INTERNACIONAL: UM ESTUDO DE CASO DO PORTO DE IMBITUBA (SC)
}

\author{
Elivelton Dore \\ SCpar Porto de Imbituba \\ Murilo da Silva de Medeiros \\ SCpar Porto de Imbituba
}

Resumo: O presente estudo de caso tem como pergunta de partida o seguinte: como se dá a gestão da aplicação do ISPS Code no Porto de Imbituba (SC)? Com esse intuito, objetiva-se conhecer a gestão da aplicação do ISPS Code no Porto de Imbituba e, para tanto, partiu-se dos seguintes objetivos específicos: contextualizar a implantação do ISPS Code no cenário internacional e brasileiro; apresentar a Autoridade Portuária do Complexo Portuário de Imbituba, a SCPar Porto de Imbituba S.A.; e caracterizar as estratégias e inovações da gestão da aplicação do ISPS Code no Porto de Imbituba. Nesse sentido, utilizou-se de um estudo de caso de caráter exploratório pautado em levantamentos bibliográficos e documentais, além de entrevista semiestruturada com o Chefe da Guarda Portuária do Porto Organizado. Ao final dos trabalhos, atestou-se que, principalmente em se tratando da aplicação do modelo de Guarda Portuária terceirizada, o Porto de Imbituba apresenta alternativas de gestão da segurança portuária que podem ser absorvidas por outros portos nacionais, dados o seu bom desempenho e resultados.

Palavra-Chave: Estudo de Caso. ISPS Code. Porto de Imbituba.

\section{INTRODUÇÃO}

O Código Internacional para Proteção de Navios e Instalações Portuárias, do inglês International Ship and Port Facility Security (ISPS) Code, vigora desde 2004 enquanto emenda da Convenção Internacional para a Salvaguarda da Vida Humana no Mar, do inglês International Convention for the Safety of Life at Sea (SOLAS), de 1974. Foi adotado no âmbito da Organização Marítima Internacional (IMO), da qual o Brasil é membro desde 1963. Tendo o Brasil ratificado à convenção SOLAS por meio do decreto 87.186/1982, em 1982, o então Presidente em 2009, Luiz Inácio Lula da Silva, vide o Decreto 6.869/2009, sancionou a implementação dos procedimentos e normas para as medidas de proteção aos navios e instalações portuárias advindas do ISPS Code (BRASIL, 2009). A partir dessa data, todos os portos organizados brasileiros inseridos no comércio internacional de mercadorias, dessa forma, deviam adequar-se ao código.

O ISPS Code estabelece responsabilidades para governos, empresas de transporte, pessoal de bordo, Autoridades Portuárias e demais agentes das rotinas portuárias de modo a "detectar ameaças à proteção e tomar medidas preventivas

*A revisão gramatical, ortográfica, ABNT ou APA foi realizada pelos autores. 


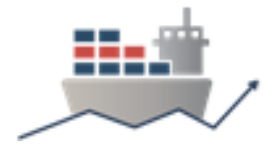

contra incidentes de proteção que afetem navios ou instalações portuárias utilizadas no comércio internacional." (IMO, 2015). Filho de um contexto de intensificação dos fluxos internacionais de comércio (DI SENA JR, 2003), de ascensão de supostos novos tipos de ameaças à segurança internacional (HOFFMAN, 1997) e de evolução gradativa e significativa das tecnologias da informação (CASTELLS, 1999) - nas quais se inserem as tecnologias relativas à segurança - O ISPS Code é um importante elemento da gestão da segurança portuária internacional na atualidade. Garantir sua correta aplicação no âmbito dos portos organizados brasileiros é imprescindível tanto para assegurar a integração e aprofundamento da inserção do Brasil nas grandes cadeias globais comerciais, quanto para garantir a segurança portuária dos portos nacionais.

O complexo portuário de Imbituba, em Imbituba (SC), dessa forma, constitui-se enquanto um dos portos organizados de referida importância e estratégia ao país. Vem, principalmente ao longo dos últimos anos, crescendo nas estatísticas de movimentação portuária e constituindo-se enquanto uma janela ao exterior, chave para a região Sul do país. Desde que o Governo do estado de Santa Catarina assumiu - Porto Organizado por meio da SCPar Porto de Imbituba S.A., as toneladas movimentadas anualmente pelo porto mais que duplicaram, passando de 2.492.026 (dois milhões, quatrocentas e noventa e duas mil e vinte e seis), em 2013, para 5.222.619 (cinco milhões, duzentas e vinte e dois mil, seiscentos e dezenove), em 2018. Em 2019, o mês de março já possibilitou a maior movimentação mensal da história do Porto de Imbituba, ou seja, mais de 592.600 (quinhentas e noventa e duas mil e seiscentas) toneladas foram movimentadas. Ao que a movimentação do primeiro trimestre indica, o ano de 2019 será o de melhor desempenho do Porto ao longo de sua existência em termos de toneladas movimentadas.

É nesse sentido que este trabalho, assimilando o Porto de Imbituba à propriamente dita aplicação do ISPS Code nos portos organizados brasileiros e a partir de um estudo de caso de caráter exploratório pautado em levantamentos bibliográficos e documentais, além de entrevista semiestruturada com o Chefe da Guarda Portuária do Porto Organizado, tem como pergunta de partida o seguinte: como se dá a gestão da aplicação do ISPS Code no Porto de Imbituba (SC)? Com vistas a tratar o problema, objetiva-se conhecer a gestão da aplicação do ISPS Code no Porto de Imbituba e, para tanto, partiu-se dos seguintes objetivos específicos: 1) contextualizar a implantação do ISPS Code no cenário internacional e brasileiro; 2) apresentar a Autoridade Portuária do Complexo Portuário de Imbituba, a SCPar Porto de Imbituba S.A.; 3) e caracterizar as estratégias e inovações da gestão da aplicação do ISPS Code no Porto de Imbituba.

\section{O CONTEXTO NACIONAL, INTERNACIONAL E O ISPS CODE}

O crescimento exponencial em termos de tecnologias da informação, comunicação e transporte ao longo dos últimos séculos, dentre outras consequências, possibilitou a ampliação dos fluxos de relacionamento entre as nações: eis o que se convencionou chamar de "globalização". Em termos comerciais-econômicos, por exemplo, cadeias globais de produção, de finanças e de comércio de bens e serviços conectam praticamente todos os lugares da terra (NOVAES, 2004).

No tocante ao escopo deste trabalho, tal contextualização se faz importante porque o potencial de ameaças à segurança advindas destas conexões e relacionamentos amplia-se de maneira significativa neste cenário internacional e interconectado, bem como também se ampliam os mecanismos e meios de mitigar, 
balancear e aniquilar tais ameaças. De uma maneira geral, ainda que discussões no tocante às novas naturezas dos elementos primordiais da área da segurança se façam presentes - como a discussão sobre as novas guerras (KALDOR, 2001), as novas ameaças (PARIS, 2001), o novo terrorismo (HOFFMAN, 1997) etc. - é certo que, pelo menos em termos de ampliação das quantidades de riscos e mecanismos à sua disposição disponíveis, a contemporaneidade trata-se de um tempo de desafios sem precedentes na história moderna.

Nesse contexto, eis que, no período final da Guerra Fria, ataques caracterizados como "terroristas" passaram a chamar maior atenção das autoridades internacionais e mídias que de costume, como o caso do sequestro do navio de passageiros Achille Lauro em 1985, o caso da explosão do Boeing 747 da Pan Am em 1988, o atentado ao World Trade Center em 1993 e o ataque com explosivos ao USS Cole em 2000. Salienta-se o período histórico em questão que, para além das ondas globalizantes, proporcionou um vácuo no que toca às grandes ameaças à segurança internacional, sobretudo ocidental, como há muito não acontecera.

Entretanto, nenhum desses eventos foi tão significativo aos rumos e desdobramentos das Relações Internacionais que o atentado de 11 de setembro de 2011 em Nova lorque e Washington. Ele mudou drasticamente as políticas internacionais de segurança. A "Guerra Global ao Terror", capitaneado pelo então presidente dos Estados Unidos (EUA), George W. Bush, resultou nas campanhas militares do Afeganistão e do Iraque, além de um enrijecimento das leis migratórias estadunidenses e da intensificação da segurança de portos e aeroportos internacionais no país. Não demorou muito para que, sob influência norte-americana, esse conjunto de procedimentos em termos de segurança fosse aplicado internacionalmente. Na posição de maior economia mundial e diante do seu peso nas Relações Internacionais, os EUA buscou envolver a comunidade internacional numa série de medidas, como incentivos a outros países para cooperarem com suas forças navais numa espécie de governança marítima global, além da Proliferation Security Initiative $^{1}$ (PSI) de 2003 e da chamada Thousand Ship Navy ${ }^{2}$ (TSN) de 2006, que congregaria forças navais, operadores portuários, armadores, agências internacionais, de governos e não governamentais, num esforço contra problemas comuns, patrulhando os mares do mundo. Dessa maneira, sob o discurso de garantir a segurança do comércio marítimo internacional em meio às ameaças terroristas, a elaboração e os esforços para internalização do ISPS Code globalmente foi um dos principais esforços convertidos em realizações por parte dos estadunidenses (ROZOFF, 2009).

Isso se deu por meio da $22^{\text {a }}$ Sessão da IMO, em dezembro de 2002, reunida na Conferência Diplomática sobre Proteção Marítima, em Londres. A Organização Marítima Internacional, ou International Maritime Organization (IMO), é uma agência especializada do Sistema das Nações Unidas criada em 1948 com o objetivo de padronizar a indústria marítima dos Estados Membros. Acrescentar-se-ia um anexo à International Convention for the Safety of Life at Sea (SOLAS), assinada no âmbito da organização em 1974 e já revisada em 1988. Este anexo tratava-se, justamente, do próprio ISPS Code (SEGRINI, 2007). O ISPC Code foi criado, assim, para que houvesse uma cooperação entre os governos que ratificaram e promulgaram a SOLAS, a fim de conferir maior segurança marítima tanto no âmbito dos navios internacionais quanto nas instalações portuárias nacionais, trazendo, então, impactos tanto para o Direito Marítimo quando para o Direito Portuário. No âmbito dos portos,

\footnotetext{
1 Iniciativa de Proliferação da Segurança.

2 "Marinha de mil navios".
} 


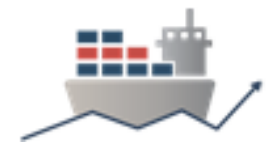

atestou-se que a extensão da aplicação do ISPS Code seria determinada pelo governo contratante, tendo em vista a natureza interna do Direito Portuário (IMO, 2015). A partir disso, o Brasil ratificou o código por meio do decreto 6.869/2009 no ano de 2009 (BRASIL, 2009).

No país, a Comissão Nacional de Segurança Pública nos Portos, Terminais e Vias Navegáveis (CONPORTOS) foi criada para ser a autoridade de maiores incumbências no tocante à gestão do código no âmbito nacional. Ela faz parte da estrutura da Secretaria Nacional de Segurança Pública (SENASP) do Ministério da Justiça, ligado á Presidência da República, desde o decreto 1507/95, de 1995. É composta por membros do Ministério da Justiça, representado pelo comando da Polícia Federal (PF); da Agência Nacional de Transportes Aquaviários (ANTAQ); do Ministério de Relações Exteriores, do Ministério da Fazenda; pelo Ministério da Defesa, representado pelo comando da Marinha do Brasil; e do Ministério dos Transportes. Ligam-se à CONPORTOS, por sua vez, as Comissões Estaduais de Segurança Pública nos Portos, Terminais e Vias Navegáveis (CESPORTOS). Estas últimas tratam diretamente com as Autoridades Portuárias dos portos organizados que são responsáveis pela elaboração, aplicação e controle do Plano de Segurança Pública Portuário dos respectivos portos. As CESPORTOS, por sua vez, constituemse a partir do Departamento de Polícia Federal, da Capitania dos Portos, do Governo do Estado, das Autoridades Portuárias e da Secretaria da Receita Federal.

Nesse sentido, constituindo-se os portos organizados enquanto estratégicos ao Estado brasileiro sob as mais diversas perspectivas, garantir sua segurança contra os elencados elementos a partir dos padrões internacionais faz-se, da mesma maneira, estratégico. Todos os portos com movimentação internacional no Brasil aplicam o ISPS Code. O Porto de Imbituba, em Imbituba (SC), configura-se enquanto um exemplo, atuando como um importante canal de comercialização entre o país - e especialmente a região Sul do estado de Santa Catarina - e o globo.

\section{A SCPAR PORTO DE IMBITUBA ENQUANTO AUTORIDADE PORTUÁRIA}

um:

Segundo a nova Lei dos Portos, um porto organizado constitui-se enquanto

[...] bem público construído e aparelhado para atender a necessidades de navegação, de movimentação de passageiros ou de movimentação e armazenagem de mercadorias, e cujo tráfego e operações portuárias estejam sob jurisdição de autoridade portuária. (BRASIL, 2013).

A administração de um porto público, assim, é exercida diretamente pela União, pela delegatária ou pela entidade concessionária do porto organizado. Em quaisquer dessas situações, faz-se necessária a figura de uma empresa - chamada de Autoridade Portuária - que, dentre outras coisas, cumpra e faça cumprir as leis, os regulamentos e os contratos de concessão; arrecade os valores das tarifas relativas às suas atividades; fiscalize e/ou execute as obras de construção, reforma, ampliação, melhoramento e conservação das instalações portuárias; fiscalize a operação portuária; autorize a entrada e saída, inclusive atracação e desatracação, o fundeio e o tráfego de embarcação na área do porto; autorize a movimentação de carga das embarcações; suspenda operações portuárias que prejudiquem o funcionamento do porto; reporte infrações e represente perante a ANTAQ, visando à instauração de processo administrativo e aplicação das penalidades previstas em lei, em regulamento e nos contratos; adote as medidas solicitadas pelas demais autoridades no porto; 
preste apoio técnico e administrativo ao conselho de autoridade portuária e ao órgão de gestão de mão de obra e organize a guarda portuária, em conformidade com a regulamentação expedida pelo poder concedente (BRASIL, 2013). Parte importante dessa regulamentação atrelada à última atribuição descrita é, justamente, a aplicação do ISPS Code.

Dito isso, cabe salientar que a empresa que exerce a função de Autoridade Portuária no Porto de Imbituba é a SCPar Porto de Imbituba S.A. ${ }^{3}$. Trata-se de uma empresa pública do estado de Santa Catarina, subsidiária do acionista único SC Participações e Parcerias. Exerce tal função desde o fim do ano 2012, quando recebeu a concessão do Governo Federal, antes exercida pela Companhia Docas de Imbituba (CDI), cuja atuação remonta ao ano 1941 (SCPAR PORTO DE IMBITUBA S.A., 2018a).

Em termos de estrutura, o complexo portuário de Imbituba, administrado pela SCPar Porto de Imbituba S.A., conta três berços de atracação, todos de caráter público. Possui uma área total de $4.332 .406 \mathrm{~m}^{2}$, dividida entre uma área terrestre de 1.237.796 $\mathrm{m}^{2}$ e uma área marítima de $3.094 .610 \mathrm{~m}^{2}$. Sua enseada aberta abriga um molhe de $850 \mathrm{~m}$. Possui instalações especiais para granéis líquidos, carga geral e contêineres, mas também é capaz de movimentar granéis sólidos, incluindo grãos agrícolas, uma das mercadorias chave para o porto. Ao todo, possui um Terminal de Contêiners (TECON), um Terminal de Fertilizantes e de Ração Animal (TERFER), um Terminal de Carga Geral (TCG), um Terminal de Granéis Sólidos (TGS) e um Terminal Frigorífico (TERFRIO) (SCPAR PORTO DE IMBITUBA S.A., 2018b). A imagem 1 apresenta em formato de mapa aéreo a zona primária do Porto de Imbituba, delimitando sua área terrestre e marítima e também seus terminais (SCPAR PORTO DE IMBITUBA S.A., 2018b).

Figura 1 - Zona primária do Porto de Imbituba

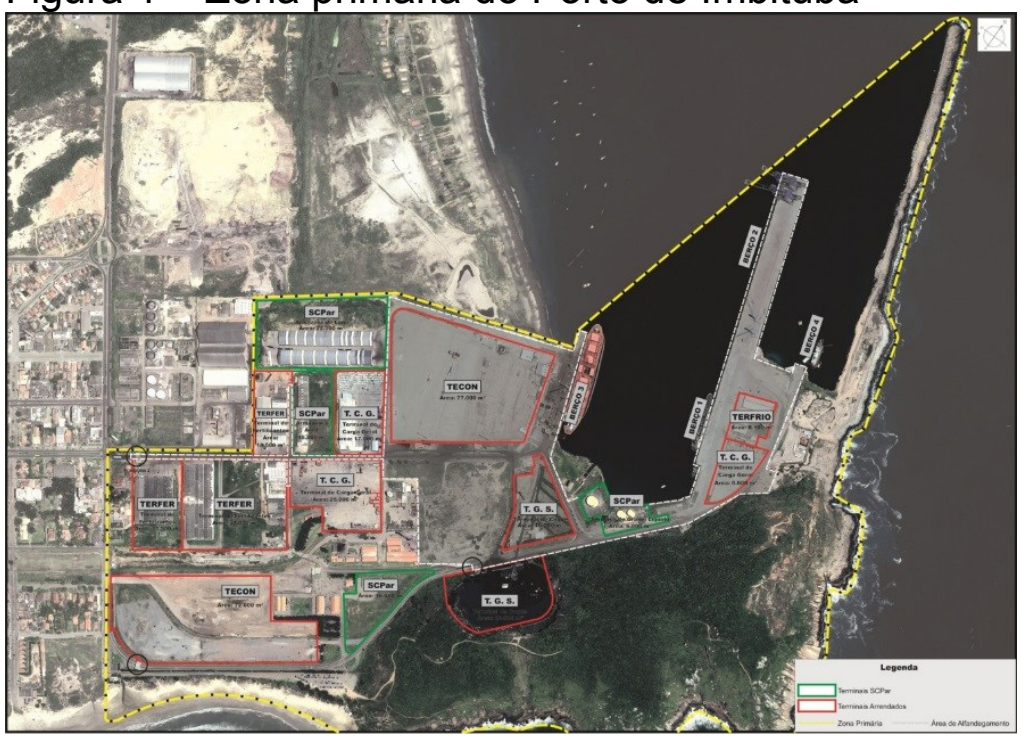

Fonte: fornecido pelo Setor de Patrimônio da SCPar Porto de Imbituba S.A., 2018.

\section{GESTÃO DA APLICAÇÃO DO ISPS CODE NO PORTO DE IMBITUBA}

\footnotetext{
${ }^{3}$ Localiza-se na Av. Presidente Vargas, n 100 , no Centro de Imbituba (SC).
} 


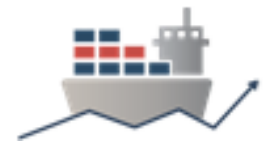

Com vistas a caracterizar as estratégias e inovações da gestão da aplicação do ISPS Code no Porto de Imbituba, optou-se por dividir a seção em três partes: na primeira delas, é realizado um disclaimer acerca do atual processo de implantação do ISPS Code no Porto de Imbituba, o que não se constitui enquanto uma inovação ou grande estratégia, mas faz-se importante de ser apresentado de modo a seguir-se adiante na temática; na segunda, apresenta-se a estrutura organizacional de gestão e gerenciamento do ISPS Code no Porto de Imbituba e, por último, seus devidos instrumentos de planejamento estratégico.

\subsection{Implantação do ISPS Code}

Tanto os navios que atracam no Brasil quanto as próprias instalações portuárias nacionais necessitam adequar-se ao ISPS Code. Uma vez cumpridos os requisitos mínimos legais para tanto, a certificação de validação é conferida. Tudo isso gira em torno do Plano Nacional de Segurança Pública Portuária brasileiro, gerido pela CONPORTOS. Em se tratando dos navios, a certificação é de atribuição da Marinha do Brasil. Já as instalações portuárias são certificadas pela própria CONPORTOS. As Autoridades Portuárias, nesse sentido, devem elaborar e implementar o sistema de prevenção e repressão a atos ilícitos nos portos, terminais e vias navegáveis (BRASIL, 2013).

Nesse sentido, a CONPORTOS, com o auxílio das CESPORTOS, dividem a implementação do ISPS Code nos portos organizados brasileiros a partir de três fases: 1) a avaliação de vulnerabilidade, 2) a colocação em prática do Plano de Segurança Portuária e 3) a concessão da certificação. Na primeira fase, os próprios portos e terminais apresentam uma avaliação de risco, uma espécie de diagnóstico e análise dos mais variados riscos iminentes às instalações portuárias do porto organizado. Ao ser aprovada, submete-se à avaliação o Plano de Segurança Portuária, propriamente dito, constando das ações, procedimentos e equipamentos a serem utilizados em relação às ameaças e riscos levantados. Após a aprovação, a Autoridade Portuária executa, propriamente dito, o planejado, sendo avaliada de forma in loco em relação ao cumprimento das diretrizes estabelecidas e, em caso positivo, tem a emissão de seu certificado de adequação ao ISPS Code emitido, isto é, a Declaração de Cumprimento (DC) (RABÊLO FILHO, 2007).

Em se tratando do Porto de Imbituba, o Plano de Segurança Pública Portuária (PSPP) vigente é de 2004, herdado da antiga administradora do porto, isto é, a Companhia Docas de Imbituba (CDI). Como o plano é proveniente de uma empresa distinta da atual Autoridade Portuária, a SCPar Porto de Imbituba não possui, no momento, a Declaração de Cumprimento (DC) referente ao ISPS Code, ainda que suas práticas estejam de acordo com o código. Entretanto, possui um Termo de Aptidão (TA), que indica o cumprimento da normativa em questão, ainda que não em sua completude (ESTEVES, 2007).

Com vistas a regularizar a sua situação, em 2017 a empresa lançou um processo licitatório para a contratação de uma organização de segurança credenciada pela CONPORTOS para a elaboração do estudo de avaliação de risco (EAR) e elaboração do novo Plano de Segurança Pública Portuária. A empresa HNS Consulting e Security LTDA - EPP foi, então, contratada a partir do Contrato 043/2017. Atualmente, o mesmo encontra-se encerrado, tendo sido cumprido em sua totalidade por parte da prestadora de serviço.

Dessa forma, capitaneado pela HNS, pela Guarda Portuária e pela Unidade de Segurança, elaborou-se a análise de riscos do Porto de Imbituba, encaminhada à 


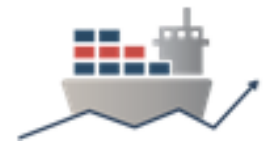

CONPORTOS e aprovada no ano de 2018. Após, elaborou-se o novo Plano de Segurança Pública Portuária, este relativo à nova Autoridade Portuária da empresa, e o mesmo também fora submetido à CONPORTOS, não tendo sido, até o presente momento, aprovado pela comissão.

Assim, o status atual da SCPar Porto de Imbituba é o seguinte: possui um PSPP vigente relativo à antiga Autoridade Portuária, portanto, precisando aprovar um novo PSPP. Sua análise de risco fora aprovada pela CONPORTOS e aguarda a mesma comissão aprovar seu novo PSPP, elaborado sob a consultoria de uma empresa contratada vide processo licitatório. Nesse momento, o porto está pleiteando sua certificação, isto é, a DC, possuindo uma TA. Entretanto, este status não the impede de exercer suas funções inerentes à sua natureza, mas tão somente lhe obriga a regularizar sua situação o quanto antes perante a CONPORTOS.

\subsection{Estrutura organizacional}

A SCPar Porto de Imbituba organiza-se quanto à segurança portuária a partir da perspectiva clássica adotada no setor portuário, isto é, a que diferencia "safety" " "security"4. Segundo Albrechtsen (2003), de modo geral, "safety" diz respeito à proteção contra incidentes aleatórios, ou seja, aqueles indesejados que acontecem como resultado de uma ou mais coincidências em eventos cotidianos. Por sua vez, "security" diz respeito à proteção contra incidentes planejados, ou seja, que acontecem devido a um resultado deliberado e ato planejado de outrem. A Convenção Internacional para Salvaguarda da Vida Humana no Mar de 1974, revisada em 1988, trata, de maneira geral, do que comumente se entende por "safety" no setor portuário, ou seja, a salvaguarda da vida humana no mar, a capacitação e treinamento de tripulantes, o controle e monitoramento dos aparelhos de navegação, alarmes e sistemas de comunicação, a segurança e adequação da infraestrutura de acessos terrestre e aquaviário e a atracação de navios (IMO, 1974). Foi somente a partir do ISPS Code, em 2002, que a convenção passou a tratar de forma mais clara e incisiva de assuntos diretamente ligados à "security", ou seja, a proteção, controle e monitoramento na interface porto/navio, no trânsito portuário de pessoas, passageiros, tripulantes, cargas e bagagens e no apoio e abastecimento às embarcações (IMO, 2015).

Dessa maneira, dois setores ligados à segurança portuária coexistem na empresa: o primeiro, ligado à "safety", trata-se do Setor de Saúde, Segurança e Meio Ambiente. O segundo, ligado à "security", trata-se da Unidade de Segurança e a Guarda Portuária integrante deste setor. Ambos os setores, no organograma da empresa, estão subordinados à "Diretoria do Presidente" da SCPar Porto de Imbituba, conforme o organograma sintético constante a figura 2. Entretanto, somente a Unidade de Segurança interessa a este trabalho a partir do nicho de estudo proposto.

\footnotetext{
${ }^{4}$ Ambas traduzindo-se na Língua Portuguesa enquanto "segurança", portanto sem distinção conceitual clara na língua, o que leva à utilização dos termos em Língua Inglesa pela literatura.
} 
Figura 2 - Recorte de organograma sintético da SCPar Porto de Imbituba S.A.: Unidade de Segurança

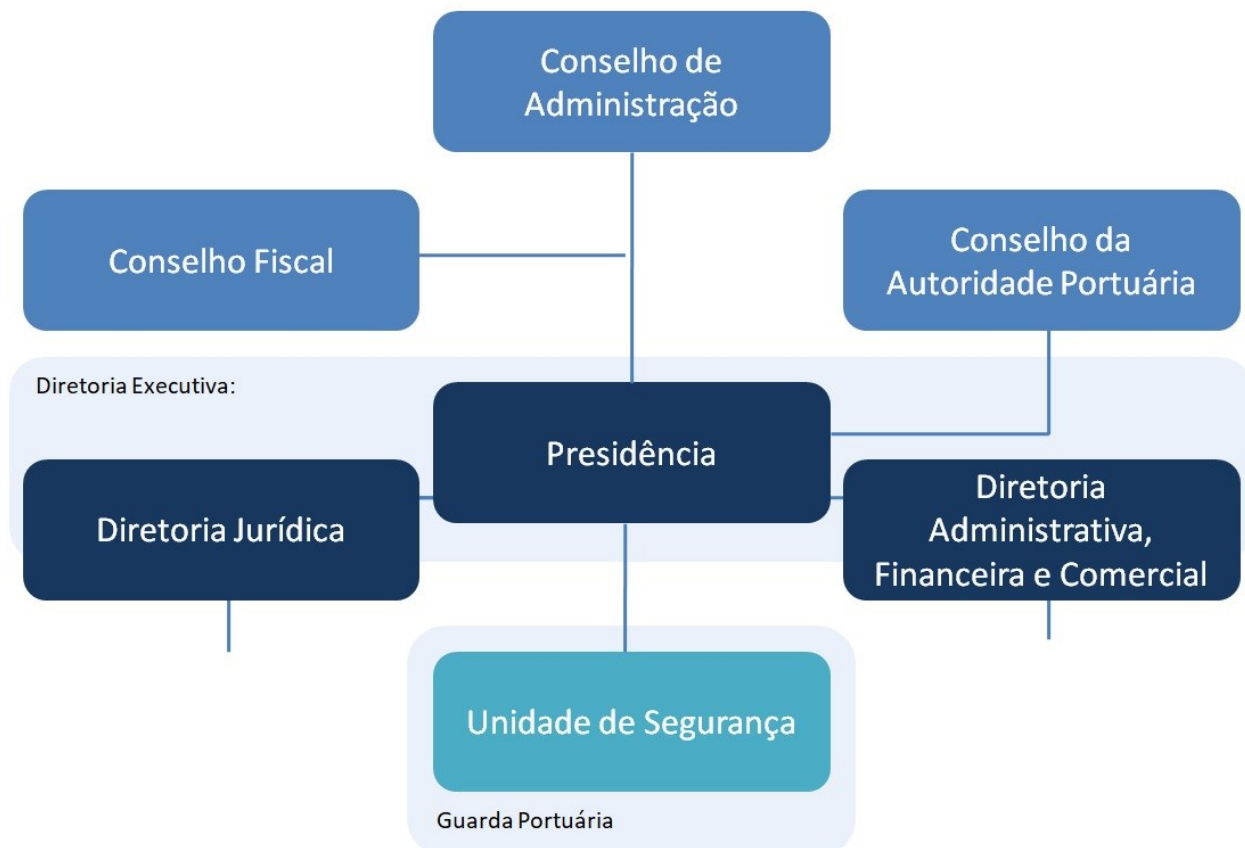

Fonte: adaptado de organograma fornecido pelo Setor de Recursos Humanos da SCPar Porto de Imbituba S.A., 2018.

Cabe à Unidade de Segurança, setor primário e prioritário da empresa nas tratativas relacionadas ao ISPS Code, garantir o acesso público, controlado e restrito de pessoas e veículos nas dependências do Porto; delimitar e sinalizar as áreas para os equipamentos em suas dependências; apontar seus pontos sensíveis e de vulnerabilidades; instalar e manter a iluminação de segurança; promover sua constante vigilância; formar e treinar os seus profissionais no tocante aos aspectos de segurança portuária; promover a adequada identificação de tripulantes e passageiros das embarcações; inspecionar e controlar os documentos e manifestos de cargas; garantir os devidos processos e procedimentos de segurança, dentre outras atribuições. (AGIL; CDI; CRB; FERTISANTA, 2004).

Em termos de pessoal, a Unidade de Segurança organiza-se a partir de um Coordenador de Segurança Portuária (CSP) que exerce a função de Chefe da Guarda Portuária (CGP) e gestor do setor. O referido colaborador, na figura de autoridade no Porto de Imbituba no tocante aos assuntos de sua segurança, embora subordinado organizacionalmente ao Diretor Presidente da empresa, foi entrevistado pelo presente autor a partir de um questionário semiestruturado no dia 19 de dezembro de 2018. Suas respostas, além de informações fornecidas por demais setores da empresa, como o Setor de Recursos Humanos, bem como das legislações e documentações oficiais pertinentes em vigência, compõem a base das fontes de pesquisa deste trabalho, conforme já elencado na introdução.

Além do referido colaborador, outros dois estão devidamente capacitados para exercer a função de CSP no porto, um deles tratando-se de um colaborador de carreira concursado e outro se tratando de um colaborador comissionado.

A função de CSP e CGO diz respeito, conforme o Plano de Segurança Portuária (PSP) em vigência na organização, a, dentre outras coisas, dirigir em nome da Administração do Porto todas as atividades de segurança e controle em seus 


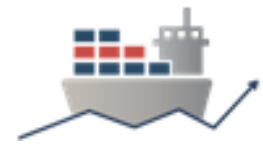

recintos, assessorar a administração portuária nos assuntos de segurança e controle, aplicar as normas federais, estaduais e municipais no tocante à segurança portuária, supervisionar, coordenar e controlar todas as ações de vigilantes, registrar todas as ocorrências e realizar os devidos procedimentos para sanar os problemas delas decorrentes, controlar o acesso de pessoas e veículos nas dependências do Porto etc. (AGIL; CDI; CRB; FERTISANTA, 2004).

Além do CSP/CGP, o setor possui um Coordenador de Acesso, responsável pelo gerenciamento do controle de acesso nas dependências do Porto, sob a égide do CSP/CGP, e um Administrativo Portuário, colaborador concursado de nível Ensino Médio cuja função é assistir aos CSP e ao Coordenador de Acesso. Dessa forma, visualiza-se que a Unidade de Segurança trata-se de um setor bastante pequeno, constituindo-se por três colaboradores. Entretanto, isso acontece em virtude de uma peculiaridade típica do Porto de Imbituba, isto é, a Guarda Portuária terceirizada.

Nessa linha, são inúmeras as necessidades advindas do ISPS Code. Uma unidade de segurança com competência sobre a área jurisdicional do porto, observando a forma e a finalidade, no exercício das atribuições, limitando ou disciplinando os direitos, interesses ou liberdades, regulando a prática de ato ou a abstenção de fato, em razão do interesse público, assim, se faz imprescindível na estrutura da organização portuária. Considerando que tal unidade de segurança, em sua atuação concernente à segurança, à higiene, à ordem, aos costumes, à disciplina, evite os abusos ou os desvios de poder, tal unidade, por força de lei, "só pode ser a Guarda Portuária" (JÚNIOR, 2014, p. 20).

Segundo o regimento interno da Guarda Portuária do Porto Organizado de Imbituba,

\begin{abstract}
O sistema de Segurança do Porto Organizado de Imbituba, administrado pela SCPar Porto de Imbituba S.A., é composto por Segurança Orgânica, Vigilância Patrimonial, Vigilância Eletrônica (monitoramento por sistema de CFTV), Sinais de Alarme, Sistema de Comunicação, Sistemas Informatizados de Cadastramento e Controle de Acesso de Pessoas Veículos e Cargas, Barreiras Físicas, Equipamentos de Detecção de Metais, Normas, Procedimentos, Integração e Cooperação com Autoridades de Segurança Pública e Órgãos Intervenientes (PORTO ORGANIZADO DE IMBITUBA, 2015)
\end{abstract}

Ainda segundo o regimento, "a Guarda Portuária - GUAPOR é uma Unidade de Segurança pertencente à estrutura organizacional da SCPar Porto de Imbituba S.A., subordinada diretamente ao Diretor Presidente [...]". Assim, "O Gerente da Guarda Portuária, empregado do quadro próprio ou de livre nomeação, é nomeado pelo Diretor Presidente".

Quanto à estrutura organizacional da Guarda Portuária, além de ser composta pelos membros da Unidade de Segurança, setor da Autoridade Portuária anteriormente tratado e que é formado por um CSP e CGP, um coordenador de acesso e um assistente administrativo, também é formada por cinquenta e dois vigilantes e quatro operadores de equipamentos de CFTV. Tanto os vigilantes quanto os operadores de CFTV são terceirizados, ou seja, pertencem a uma empresa contratada pela SCPar Porto de Imbituba vide um processo licitatório. Cabe salientar que os postos de trabalho da Guarda Portuária e o número de guardas em cada posto são definidos pelo próprio Diretor Presidente da empresa, portanto, o número de membro da Guarda respeita àquilo que, estrategicamente, a administração da Autoridade Portuária julga que é condizente com as necessidades em questão. Isso 


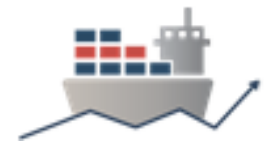

assegura certa flexibilidade e facilidade por parte da Diretoria Executiva e da Unidade Segurança em termos de gestão de pessoas se comparado ao modelo clássico nos portos públicos brasileiros, isto é, o da Guarda Portuária concursada.

Dessa maneira, esse é o efetivo do Porto Organizado de Imbituba para lidar com as questões inerentes à dimensão "security" da segurança portuária. Na visão do seu SSP, este número fica dentro da margem do que se considera suficiente e eficiente para se lidar com as ameaças apresentadas ao porto. À medida que novas demandas surgem ou mesmo desaparecem, dado o modelo adotado, isto é, o de Guarda Portuária terceirizada, faz-se muito mais simples, mais ágil e menos custoso ampliar ou diminuir o número de membros da equipe.

Quanto à atuação da Guarda, historicamente, o porto nunca passou por uma situação de segurança de nível 02 ou 03, conforme a escala em três degraus proposta pelo ISPS Code (IMO, 2015) e também nunca foi vítima de tentativas mal ou bem sucedidas que se tenham registros oficiais de tráfico de drogas, armas, espécimes ou pessoas, contrabando ou descaminho. Dentre as ameaças já enfrentadas e devidamente registradas pelos mecanismos oficiais, destacam-se as tentativas de invasão por motivos fúteis (como banhistas em movimento e pescadores em busca de redes perdidas), a chegada de lixo a partir do oceano, o desembarque de contêineres sem o lacre original, a tentativa de falsificação de documentos, a tentativa de corrupção de membros da guarda portuária e os ataques cibernéticos. Nesse sentido, pode-se dizer que, dentro do limite de tempo em que a SCPar Porto de Imbituba atua enquanto Autoridade Portuária neste porto, o fato do mesmo contar com uma Guarda Portuária terceirizada não implica, em absoluto, em qualquer vulnerabilidade a sua própria segurança em virtude deste fato. Haja vista que não há cases de situação de segurança de nível 02 ou 03 , não se pode avaliar empiricamente a sua atuação, entretanto, com os dados disponíveis, é razoável afirmar que, no caso do Porto de Imbituba, a Guarda Portuária terceirizada vem atendendo às expectativas e demandas a ela atribuídas.

Uma outra questão diz respeito, justamente, à economia de recursos por parte da Administração Portuária atuando com uma Guarda Portuária terceirizada. O atual contrato de empresa especializada em serviços de Vigilância Orgânica da SCPar Porto de Imbituba, assinado em março de 2016 e aditivado em outras três situações posteriores, tem um valor global de $\mathrm{R} \$ 4.054 .507,20$. Ou seja, este é o valor total pago pela Autoridade Portuária à prestadora de serviço para 12 meses de trabalho. Em cinco anos, o montante da soma desse valor - sem considerarem-se outras correções e fatores de influência no preço, portanto, apenas multiplicando-se o valor apresentado por cinco - é de R $\$ 20.272 .536,00$ (SCPAR PORTO DE IMBITUBA S.A., 2016).

Na SCPar Porto de Imbituba, de acordo com o Plano de Cargos, Carreira e Salários da empresa (SCPAR PORTO DE IMBITUBA S.A., 2019), o colaborador concursado que possui a menor remuneração é o Administrativo Portuário nível I. Ao considerarem-se os valores gastos pela empresa com o seu salário base, adicional de risco portuário, FGTS mensal, INSS patronal, vale alimentação, plano de saúde, plano odontológico e as devidas proporções de suas férias e décimo terceiro salário, um Administrativo Portuário custa à SCPar Porto de Imbituba R $7.110,55$ ao mês. Em um ano, este colaborador custa $\mathrm{R} \$ 85.326,60$ à empresa. Em cinco anos, o valor dos custos desse colaborador vai para $\mathrm{R} \$ 426.633,00$.

Aproximando os valores gastos pela empresa a partir da Guarda Portuária terceirizada com uma hipotética situação em que os Guardas Portuários fossem concursados, enquadrando-se enquanto Administrativos Portuários de nível I, isto é, 
o cargo concursado de menor remuneração na empresa, multiplica-se os 52 vigilantes e os 4 operadores de CFTV pelo valor global gasto pela Autoridade Portuária em cinco anos com um Administrativo Portuário. Nesse caso, obtêm o valor de $R \$ 23.891 .448$. Isto é, a economia, em cinco anos, a partir da contratação de uma Guarda Portuária terceirizada, se comparada à Guarda Portuária concursada, nos termos aqui tratados, é estimada em $\mathrm{R} \$ 3.618 .921$, um valor relativamente significativo aos cofres públicos e que se constitui, per si, enquanto um importante indicador da qualidade do modelo de terceirização da Guarda.

\subsection{Instrumentos de planejamento estratégico}

Em se tratando de gestão da segurança no Porto de Imbituba, especificamente tratando da segurança em sua dimensão "security", cabe trazer à tona o Planejamento Estratégico de Longo Prazo (PELP) - 2019-2023 da empresa (SCPAR PORTO DE IMBITUBA S.A., 2018b). Isto porque este documento trata-se de um importante instrumento de gestão que norteia a execução das ações da empresa dentro daquilo que lhe é cabida na figura de Autoridade Portuária ao longo dos anos seguintes. O PELP conversa com os demais instrumentos estratégicos da empresa, dos quais cabe mencionar p Plano Mestre (SNPTA, 2018) e o Plano de Negócios (SCPAR PORTO DE IMBITUBA S.A., 2018c).

Dessa forma, no tocante à Unidade de Segurança, eis que o objetivo estratégico único é "Garantir o cumprimento das normas internacionais de segurança portuária (ISPS - Code).”. Salienta-se, assim, a existência do setor para o cumprimento do código. Para tanto, ou seja, garantir o cumprimento do ISPS Code, três são os indicadores apurados de forma mensal, isto é: 1) o número de ocorrência de ilícitos penais tipificados no ISPS-CODE (cujo objetivo é zerar mensalmente, ou seja, chegar a 0), 2) a quantidade de ocorrências solucionadas (cujo objetivo é totalizar mensalmente, ou seja, chegar a $100 \%$ delas) e 3) o número de não conformidades graves com o ISPS-CODE (cujo objetivo é zerar mensalmente, ou seja, chegar a 0) (SCPAR PORTO DE IMBITUBA, 2018b).

O histórico de ocorrências, ocorrências solucionadas e não conformidades graves, infelizmente, não se trata de uma informação pública, restringindo-se à cúpula administrativa da Guarda Portuária da empresa e, por isso, os documentos não puderam ser acessados para devido aferimento por este trabalho. Entretanto, o plano de ação para se alcançar os objetivos dos indicadores está acessível e, no tocante ao primeiro indicador, a ação primordial é o registrar os incidentes e monitorar o andamento de suas soluções. Os passos são os seguintes: a Guarda Portuária monitora constantemente a área do Porto Organizado e, diante de um incidente, toma os procedimentos de segurança contidos no Plano de Segurança. Toda a comunicação entre seus membros é feita via rádio em canais secretos e inacessíveis ao público externo. Após, registra os fatos por meio de Comunicação Interna $(\mathrm{Cl})$, sendo esta encaminhada às áreas envolvidas com o apoio do software Sistema de Gestão e Protocolo Eletrônico (SGPE). A Unidade de Segurança monitora o andamento da solução do problema, havendo, para tanto, um conjunto de prazos máximos em uma escala de prioridades para cada tipologia de ocorrência (SCPAR PORTO DE IMBITUBA, 2018b).

Em se tratando do segundo indicador aferido, três são as ações previstas. As duas primeiras ligam-se diretamente a apontamentos da Comissão Nacional de Segurança Pública nos Portos, Terminais e Vias Navegáveis (CONPORTOS) realizados em auditorias anteriores, ou seja, atender ao item 47 do anexo I da 


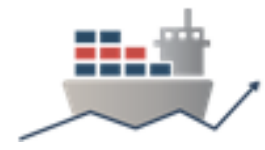

Resolução 047/2011 da CONPORTOS (CONPORTOS, 2011). A última ação relaciona-se diretamente ao mantimento atualizado do Plano de Segurança Portuária (PSP). Para tanto, visa-se a comunicar a CESPORTOS sobre as mudanças que envolvem o perímetro do porto, incluindo o sistema de CFTV; participar das reuniões de segurança organizadas mensalmente pela CESPORTOS envolvendo todo o complexo portuário de Santa Catarina e realizar as auditorias internas trimestralmente previstas no Plano de Segurança, em cumprimento da Portaria 001/2016 da comissão (SCPAR PORTO DE IMBITUBA, 2018b).

Por fim, quanto ao último indicador, as ações previstas aplicam-se de maneira genérica, priorizando o monitoramento 24 horas ao dia de toda a área portuária por meio de sistema de Circuito Fechado de Televisão (CFTV), as rondas pela Guarda Portuária também em horário integral e por toda a área portuária e uma política de treinamentos contínuos e continuados, inclusive com exercícios e simulados (SCPAR PORTO DE IMBITUBA, 2018b).

De maneira geral, em relação ao nível tático valorizado no planejamento que, via de regra, deve aplicar-se no nível estratégico - pode-se dizer que se trata daquilo que pode ser publicizado sem maiores riscos à segurança do porto. No que toca ao tema aqui em discussão, ou seja, a segurança portuária, nas palavras do SSP entrevistado, a maior parte das decisões e medidas estratégicas tomadas ou planejadas não podem ser externalizadas, sob pena de colocar-se em xeque o próprio planejamento estratégico em relação à segurança do porto.

Além disso, no que toca à gestão - apartando-se meramente do gerenciamento - cabe destacar a valorização dada pelo porto, na figura de seus instrumentos estratégicos, aos treinamentos, capacitações e simulados, demonstrando uma preocupação de facto com a qualificação do pessoal em trabalho na Unidade de Segurança e Guarda Portuária.

\section{CONSIDERAÇÕES FINAIS}

O presente trabalho teve como ponto de partida a seguinte questão: como se dá a gestão da aplicação do ISPS Code no Porto de Imbituba (SC)? Em se tratando desse problema, cabe salientar que é bastante dificultoso realizar tal tipo de estudo de caso com um alto valor em detalhes, uma vez que 1) os principais documentos relativos à aplicação do ISPS Code em um porto, como, por exemplo, o Plano de Segurança Pública Portuária, é restrito à Guarda Portuária e Diretoria; 2) os relatórios de ocorrências são restritos à Guarda Portuária e Diretoria e 3) as informações coletadas por meio de entrevistas com os indivíduos chave na administração da segurança portuária são bastante básicas, dadas as restrições já elencadas.

Dessa maneira, cabe salientar que este estudo de caso tem origem exploratória e, portanto, é passível de aprimoramento e desenvolvimento em trabalhos futuros que visem a aferir com mais propriedade a aplicação do ISPS Code no Porto de Imbituba, mesmo diante de tais restrições de acesso às informações. $O$ maior desafio em um estudo do tipo se dá em obter as informações necessárias referente às práticas, registros e ocorrências. Isto porque, ao lidar com informações do nível da segurança portuária, portanto estratégicas para as organizações em estudo, deparase com controles de acesso bastante rígidos, uma vez que o caso contrário colocaria em risco a própria aplicação dos procedimentos de segurança do porto.

O ISPS Code, com certeza, é um importante instrumento de controle e gestão da segurança portuária a partir de aplicações locais, mas com perspectivas de garantia da segurança portuária no âmbito internacional. Além disso, sua aplicação 


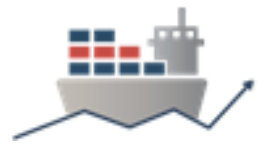

garante a inserção brasileira no importante fluxo logístico-comercial global, proporcionando à economia nacional a possibilidade de crescimento econômico com base na entrada e saída de mercadorias. Compreender a sua aplicação nos portos nacionais a partir de casos, como o aqui trazido, pode auxiliar em compreensões maiores referentes à defesa nacional e à própria segurança internacional como um todo, uma vez que portos e aeroportos constituem-se enquanto as principais portas de entrada e saída das unidades políticas e, por conseguinte, tornam-se elementos imprescindíveis no tabuleiro das ameaças e contra-ameaças globais. Constituindo-se os portos organizados de elementos essencialmente estratégicos em se tratando das mais diversas searas - que vão da econômica, comercial, de segurança e até política e social - estabelecer um controle com base no nível de lisura, padronização e responsabilidade proposto pelo ISPS Code parece ser um caminho apropriado em termos de gestão da coisa pública à disposição e sob a égide do Estado.

Por fim, no Porto de Imbituba, dentre as principais características no que toca à gestão e ao gerenciamento do ISPS Code, pode-se salientar o modelo de Guarda Portuária terceirizado, uma vez que o mesmo não é tão comum nos portos públicos brasileiros. Tal modelo rende ao Porto uma maior flexibilidade, agilidade e simplicidade na gestão de pessoas. Além disso, de maneira geral, é menos dispendioso à empresa, mesmo sem implicar em ônus por parte dos serviços prestados. Outro ponto importante a se destacar é o foco na qualificação constante do corpo de colaboradores integrantes da Unidade de Segurança e Guarda Portuária, atestado de maneira incisiva tanto no Planejamento Estratégico de Longo Prazo da empresa, quanto nos outros instrumentos estratégicos da empresa.

\section{REFERÊNCIAS}

AGIL - Armazéns Gerais de Imbituba; CDI - Companhia Docas de Imbituba; CRB Operações Portuárias; FERTISANTA - Fertilizantes Santa Catarina. Plano de Segurança Portuária. DTA Engenharia: Imbituba, 2004.

ALBRECHTSEN, Eirik. Security VS. Safety: 2003. Disponível em: $<$ https://www.iot.ntnu.no/users/albrecht/rapporter/notat $\% 20$ safety $\% 20 v \% 20$ security.p df>. Acesso em: 11 dez. 2018.

BRASIL. Decreto 6.869, de 4 de junho de 2009. Dispõe sobre a coordenação e articulação dos órgãos federais, bem como sobre os níveis de proteção dos navios e das instalações portuárias, da adoção de medidas de proteção aos navios e instalações portuárias, e institui a Rede de Alarme e Controle dos Níveis de Proteção de Navios e Instalações Portuárias, e dá outras providências. Disponível em: <http://www.planalto.gov.br/ccivil_03/_Ato2007-2010/2009/Decreto/D6869.htm>. Acesso em: 07 dez. 2018.

. Lei Federal 12.815, de 5 de junho de 2013. Dispõe sobre a exploração direta e indireta pela União de portos e instalações portuárias e sobre as atividades desempenhadas pelos operadores portuários. Diário Oficial da União, Poder Executivo, Brasília, DF, 5 jun. 2013.

CONPORTOS - Comissão Nacional de Segurança Pública nos Portos, Terminais e Vias Navegáveis. Plano Nacional de Segurança Pública Portuária. CONPORTOS: Brasília, 2002.

Resolução 12/2003. Orientação para elaboração das normas de controle de acesso e circulação de pessoas e veículos - NAPV. Disponível em: 
VI CIDESPORT/2019

Congresso Internacional

de Desempenho Portuário

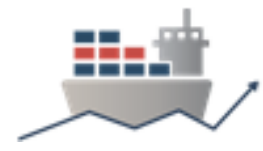

<http://www.pf.gov.br/servicos-pf/seguranca-portuaria/arquivos-e-normas/napv.pdf>. Acesso em: 7 dez. 2018.

Resolução 47/2011. Dispõe sobre critérios para a realização de auditorias nas instalações portuárias, em conformidade com o Código Internacional de Proteção de Navios e Instalações Portuárias - ISPS Code, e dá outras providências. Disponível em:

<http://www.lexeditora.com.br/doc_22839385_RESOLUCAO_N_47_DE_7_DE_ABRI L_DE_2011.aspx>. Acesso em: 7 dez. 2018.

CASTELLS, Manuel. A sociedade em rede. São Paulo: Paz e Terra, 1999.

DI SENA JR, Roberto. Comércio Internacional e globalização: a cláusula social na OMC. Curitiba: Joruá, 2003.

ESTEVES, Ricardo Zonato. Repercussões da contenção da ameaça do terrorismo internacional na economia brasileira. Revista Brasileira de Inteligência, Brasília, v.3, n.4, p. 93-98, set. 2007. Disponível:

<http://www.abin.gov.br/conteudo/uploads/2018/05/RBI4-Artigo9-

REPERCUSS\%C3\%95ES-DA-CONTEN\%C3\%87\%C3\%830-DA-AMEA\%C3\%87A-

DO-TERRORISMO-INTERNACIONAL-NA-ECONOMIA-BRASILEIRA.pdf>. Acesso em: 11 dez. 2018.

HOFFMAN, Bruce. The modern terrorist mindset: tactics, targets and

Technologies. Columbia: Columbia International Affairs Online Working Paper, 1997.

IMO - International Maritime Organization. Convenção Internacional para

Salvaguarda da Vida Humana no Mar: SOLAS. 1974. Disponível em:

<https://www.ccaimo.mar.mil.br/sites/default/files/solas_indice-2014_2.pdf>. Acesso em: 8 dez. 2018.

ISPS Code. Londres: IMO, 2015.

JÚNIOR, Nataniel da Silva. As Guardas Portuárias na regulamentação da Segurança Pública Portuária. ANTAQ/FGV: Brasília, 2014.

KALDOR, Mary. New e old wars: organized violence in a global era. California: Stanford University Press, 2001.

NOVAES, Antônio Galvão. Logística e gerenciamento da cadeia de distribuição. São Paulo: Elsevier, 2004.

PARIS, Roland. Human Security: paradigm shift or hot air? International Security, 2001, v. 26, n. 2, pp. 87- 102.

PORTO ORGANIZADO DE IMBITUBA. Regimento interno da Guarda Portuária do Porto Organizado de Imbituba. SCPar Porto de Imbituba: Imbituba, 2015.

RABÊLO FILHO, Ricardo Luiz Naves. Regimes Internacionais e segurança do modal de transporte aquaviário-marítimo em um mundo globalizado: o ISPS Code no Porto de Aratu-Candeias e no Porto de Salvador. 2007. $131 \mathrm{f}$.

Dissertação (Mestrado em Administração) - Universidade Federal da Bahia, Salvador, 2007.

ROZOFF, Rick. Control ff the world's oceans, prelude to war? Proliferation Security Initiative (PSI) and the US 1,000-ship navy. Global Research, Montreal, jan. 2009. 
VI CIDESPORT/2019

Congresso Internacional

de Desempenho Portuário

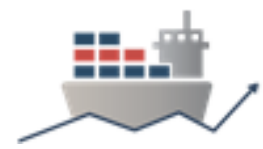

Disponível em: <http://www.globalresearch.ca/index.php?context=va\&aid=12102>. Acesso em: 5 dez. 2018. 2009.

SCPAR PORTO DE IMBITUBA S.A. A SCPar Porto de Imbituba S.A. Disponível em: <http://www.portodeimbituba.com.br/site/quem-somos/>. Acesso em: $10 \mathrm{dez}$. 2018a.

Contrato de prestação de serviços $\mathrm{N}^{\circ}{ }^{3}$ 30/2016, que entre si celebram a SCPar Porto de Imbituba S.A. e Vigilância Triângulo Ltda. 2016. Disponível em: <http://www.portodeimbituba.com.br/site/licitacoes.php>. Acesso em: 15 jan. 2019.

Imbituba: Imbituba, 2018b.

. Planejamento Estratégico de Longo Prazo: PELP. SCPar Porto de

SEGRINI, Felippe Servenini. O ISPS Code no Brasil e a sua importância para a certificação internacional do Navio e da Instalação Portuária. Jus, mar. 2007. Disponível em: <https://jus.com.br/artigos/57330/o-isps-Code-no-brasil-e-a-suaimportancia-para-a-certificacao-internacional-do-navio-e-da-instalacao-portuaria>. Acesso em: 5 dez. 2018. 2009.

Plano de Cargos, Carreira e Salários. 2019. Disponível em: <http://intranet.portodeimbituba.com.br/download/>. Acesso em: 15 jan. 2019.

Plano de Negócios Anual: 2018c. Disponível em:

<http://intranet.portodeimbituba.com.br/download/>. Acesso em: 10 dez. 2018.

SECRETARIA NACIONAL DE PORTOS E TRANSPORTES AQUAVIÁRIOS (SNPTA). Plano Mestre: Complexo Portuário de Imbituba. 2018. Disponível em: <http://www.transportes.gov.br/images/SNP/planejamento_portuario/planos_mestres /versao_completa/pm12.pdf>. Acesso em: 15 abr. 2019. 